\title{
La Administración Pública y Naciones Unidas (II)
}

\author{
Jaime Rodríguez-Arana Muñoz \\ Vocal español de la Comisión de Expertos de \\ Naciones Unidas en Administración Pública
}

\begin{abstract}
SUMARIO: VII. LA ADMINISTRACIÓN PÚBLICA Y LA LUCHA CONTRA LA POBREZA. VIII. DATOS BÁSICOS SOBRE EL SECTOR PÚBLICO. IX. CONCLUSIONES DE LA REUNIÓN ANUAL DEL COMITÉ DE EXPERTOS (2003). X. LA REVITALIZACIÓN DE LA ADMINISTRACIÓN PÚBLICA COMO UNA MEDIDA ESTRATÉGICA PARA EL DESARROLLO HUMANO SOSTENIBLE. XI. EL PAPEL DE LOS RECURSOS HUMANOS EN LA REVITALIZACIÓN DE LA ADMINISTRACIÓN PÚBLICA. XII. REVITALIZACIÓN Y SOCIEDAD DEL CONOCIMIENTO. XIII. REVITALIZACIÓN DE LA ADMINISTRACIÓN PÚBLICA EN ÁFRICA. XIV.A REVITALIZACIÓN Y COOPERACIÓN. XV. REVITALIZACIÓN DE LA ADMINISTRACIÓN PÚBLICA Y ESTADÍSTICA. XVI. ACTIVIDADES DE N.U. EN MATERIA DE ADMINISTRACIÓN PÚBLICA. XVII. SOBRE EL TRABAJO DE LA COMISIÓN DE EXPERTOS.
\end{abstract}

\section{LA ADMINISTRACIÓN PÚBLICA Y LA LUCHA CONTRA LA PO- BREZA}

Si hay uno de los objetivos de la Declaración del Milenio que ha dado lugar a ríos de tinta, comentarios y glosas sin parangón, ese es el de eliminar la "pobreza abyecta y deshumanizadora que actualmente oprime a más de 1000 millones de personas" 105 . Y, para esta ingente tarea, es imprescindible contar con instituciones públicas sólidas formadas por personas con muy buena competencia y adecuada preparación. Por eso, todos los objetivos de desarrollo del Milenio, pero esencialmente la lucha contra la pobreza, dependen fundamentalmente de la eficacia y eficiencia de las instituciones, especialmente a nivel nacional.

\footnotetext{
105 Ibidem.
} 
Como es sabido, junto a la lucha contra la pobreza ${ }^{106}$, la Declaración del Milenio señaló tres grandes desafíos: "la guerra, junto a la violencia en los conflictos civiles o las armas de destrucción masiva, es el problema fundamental de la vida en un planeta al que las dificultades humanas han causado daños irreparables y cuyos recursos no son ya suficientes para satisfacer las necesidades humanas. Y, finalmente, la insuficiencia de medios eficaces en Naciones Unidas para hacer frente a los desafíos anteriores" ${ }^{107}$.

Estos desafíos se corresponden en muchos casos, África entre ellos, a que "la debilidad de las estructuras institucionales y la insuficiencia de la capacidad de los principales participantes, tanto del gobierno como de la sociedad civil” ${ }^{108}$.

Es decir, no es fácil instrumentar políticas públicas orientadas a hacer efectivos los desafíos de la Declaración del Milenio. Por ello, la debilidad institucional no contribuye a una buena preparación de los funcionarios, no fomenta el entendimiento con los agentes sociales y, lo que es más importante, resulta incapaz para chequear permanentemente las necesidades colectivas de la gente, con el fin de complementar las políticas públicas necesarias en cada momento.

Desde el punto de vista metodológico, los objetivos de la Declaración del Milenio, como se reconoce en el Documento que comentamos, deben ser contemplados desde cinco puntos de vista: ${ }^{109}$.

Primero: dichos objetivos deben asumir una dimensión local, pasar de lo universal a lo particular. Segundo: la interpretación de los objetivos de desarrollo del Milenio tienen un ámbito mucho más amplio que cualquier iniciativa comparable. Tercero: los objetivos en si mismos tienen una baja prioridad en el programa de desarrollo de los países individuales, a menos que se asocien a otras iniciativas, como los informes sobre el desarrollo humano nacional, y en especial a los documentos de estrategia de lucha contra la pobreza. Cuarto: las capacidades de los países en desarrollo no son adecuadas para abordar las complejas cuestiones y las repercusiones de los objetivos de desa-

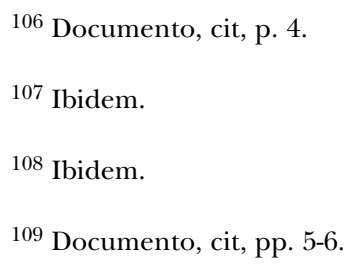


rrollo, incluso cuando se plantean como prioridades nacionales y figuran en el programa de los países. Y quinto: la base de datos para hacer análisis y formular políticas en el plano nacional es insuficiente para abordar efectivamente los objetivos de desarrollo del Milenio en el plano nacional.

Así las cosas, parece obvio señalar que el seguimiento y ejecución de los objetivos de Milenio queda en manos de las capacidades institucionales de la Administración pública de cada país, lo cual plantea graves problemas por lo que a los países en desarrollo se refiere. $\mathrm{Si}$ a esto añadimos que, en muchos casos, las reformas del sector público se produjeron, a partir de 1990, bajo el paraguas del dominio absoluto del mercado y de la afirmación de que el Estado debe reducirse en todos los casos, nos encontramos, sobre todo en los países en desarrollo, con una Administración pública raquítica y, como efecto necesario del dominio del mercado, con personal mal preparado y con insuficiente capacidad intelectual, incluso en algún supuesto una mal entendida descentralización liquidó los organismos centrales encargados de las políticas públicas de equidad y solidaridad, abriéndose las puertas a la disgregación y, en todo caso, a la pérdida de la calidad de los servicios públicos generales como puede ser la educación a la sanidad.

Por lo que se refiere a la reducción de la pobreza, el documento señala que, para atender este desafío, la Administración pública debe ser más participativa y receptora, más capacitada, más intuitiva; más abierta y transparente y, finalmente, más facilitadora, más impulsora y más justa ${ }^{110}$. También el Documento hace referencia a que debe ser un objetivo general en el que, lógicamente, correspondiendo al Estado la definición y acotación de las políticas a seguir, los Entes territoriales serán los encargados de su ejecución en sus demarcaciones territoriales. Por eso "es esencial introducir y mantener una cooperación defectiva entre ministerios y organismos" 111 de manera que los organismos centrales cuenten con un sistema sólido de gestión de la información para seguir los progresos generales de aplicación de las políticas y programas, evaluar el desempeño de los ministerios competentes, proporcionar datos para la adopción de decisiones políticas y gestionar la rendición de cuentas de los recursos utilizados ${ }^{112}$.

\footnotetext{
${ }^{110}$ Documento, cit, p. 7.

${ }^{111}$ Ibidem.

112 Ibidem.
} 
En este plano de cooperación, la descentralización hace posible que los Entes territoriales, con las oportunas transferencias de medios personales y materiales, se involucren y responsabilicen en la ejecución de los programas a desarrollar en sus territorios.

En concreto, entre las políticas dirigidas a que en el 2020 mejoren las condiciones de vida de cien millones de personas que viven en tugurios, es necesario impulsar medidas orientadas a:

a) Prestar a los pobres de las zonas urbanas servicios sociales básicos como agua potable y saneamiento.

b) Velar por el desarrollo de enfoques integrados y participativos de la planificación y gestión del medio ambiente urbano.

c) Garantizar la buena gestión pública y la planificación en las zonas urbanas mediante la concreción de asociaciones entre sectores público y privado ${ }^{113 .}$

Para lograr que estas políticas públicas resplandezcan en la realidad es necesario, insisto, disponer de funcionarios bien preparados técnicamente, con mentalidad abierta, metodológica del entendimiento y sensibilidad social.

\section{DATOS BÁSICOS SOBRE EL SECTOR PÚBLICO}

El antiguo Grupo de Expertos sobre el programa de las Naciones Unidas en materia de Administración y Finanzas públicas había propuesto que la División de Economía y Administración Pública de N.U. elaborase una serie de indicadores sobre el sector público denominada World Public Sector Report: Globalización and the State que, realmente, constituía la única fuente fácilmente accesible de parámetros que expresaban la dimensión y principales funciones del sector público ${ }^{114}$.

El estudio del documento por el Comité, nos llevó a sugerir, tras manifestar lo acertado del diagnóstico, que se amplíe y mejore el actual conjunto de indicadores teniendo presente un indicador de resultados en materia de

113 Documento, cit, p. 8.

114 Documento: Información básica sobre el sector público, Informe de la secretaría, E/C 16/2003/1, p.1. 
eficiencia y responsabilidad generales de la gestión financiera del sector público, siendo conscientes del interés de evaluar el avance de los derechos humanos o el sistema judicial, así como la descentralización, la participación, la protección de la intimidad en la legislación sobre el comercio electrónico y mecanismos de protección para el sector financiero ${ }^{115}$.

El antiguo Grupo de Expertos estableció en el XIV período de sesiones unos criterios que, en colaboración con la División de Economía y Administración pública, se referían al Estado como regulador, recaudador de impuestos, producto, consumidor, fuente de transferencias y subvenciones en efectivo y empleador. Posteriormente, en el marco de los debates del XV período de sesiones, el conjunto de indicadores para medir el sector público pasó a incluir las cinco mediciones siguientes: empleo público como porcentaje de la población, consumo porcentaje del PIB, gasto público central como porcentajes del PIB, gasto público del gobierno central por tipo y función, como porcentaje del gasto total del gobierno central e ingresos tributarios del gobierno central como porcentaje del PIB $^{116}$.

Realmente, no están todos los parámetros básicos para medir el sector público, pues habría que introducir cuestiones como la descentralización o la del grado de sensibilidad frente a los derechos humanos, por ejemplo. En este sentido, en nuestra reunión de 2002 pusimos de relieve la importancia de medir otras variables como: el estado de la esfera pública, la adquisición de conocimientos, una plataforma basada en la web para el trabajo y para la vida, el desarrollo empresarial y los vínculos entre los planos local y mundial. También señalamos que los indicadores debían estar vinculados no sólo al sector público, haciéndose especial hincapié en los servicios, en el apoyo al proceso legislativo, en la responsabilidad y en las funciones de auditoría del gobierno y buscando siempre la colaboración de los organismos nacionales de estadística ${ }^{117}$. En relación con el estado del sector público propusimos tres indicadores: la propiedad estatal de medios de comunicación; la descripción de medios por los que se da a conocer al público el presupuesto gubernamental y el estado de ratificación de los derechos humanos ${ }^{118}$. Por lo que se refiere a los

\footnotetext{
${ }^{115}$ Ibidem.

${ }^{116}$ Documento, cit, p. 3.

${ }^{117}$ Ibidem.

118 Ibidem.
} 
conocimientos, nos inclinamos por cuatro parámetros: el gasto público en investigación y desarrollo como porcentaje del presupuesto militar, el número de patentes registradores internacionalmente, la tasa de matriculación escolar con los niveles educativos y la inversión extranjera directa como porcentaje de las inversiones totales ${ }^{119}$. Por lo que se refiere al trabajo y la vida propusimos, cinco indicadores: la infraestructura de las conexiones inalámbricas de banda ancha; el número de teléfonos móviles para cada cien personas, el coste de la conexión a Internet y las aplicaciones de gobierno electrónico ${ }^{120}$. En el marco del desarrollo empresarial, pensamos en las siguientes variables: el número de trámites necesarios para crear una empresa y el número de nuevas empresas como porcentaje de las ya existentes. Y, finalmente, en materia de relaciones entre las dimensiones local y mundial, se propusieron dos indicadores: el comercio exterior como porcentaje del PIB y la migración laboral neta como porcentaje de la población.

Desde un punto de vista más general, para una buena gestión de los asuntos públicos es necesario valorar conceptos y parámetros tan relevantes como la transparencia, la responsabilidad, la participación, la libertad de prensa, el acceso ciudadano a la información pública, la independencia judicial, el control del sector público, la función de los parlamentos, los sistemas de auditoría social, la participación de la gente en el funcionamiento del sector público, el grado de representatividad del sector público en relación con los marginados o la satisfacción de los ciudadanos (acceso, igualdad, calidad del servicio, coste $)^{121}$. Aunque es difícil evaluar la capacidad institucional, es preciso disponer de datos sobre el número de códigos deontológicos, el número de comisiones parlamentarias de investigación, el porcentaje del presupuesto dedicado a la formación y a la capacitación de los funcionarios públicos ${ }^{122}$.

Hoy está de moda en las políticas de reformas administrativas exhibir, como muestra del éxito alcanzado, datos de ahorro en el funcionamiento y actividad del sector público. Es probable que en algunos casos sea necesario disponer de un sector público adecuado y que ello suponga obvias reducciones. Pero, en otros casos, quizás sea preciso disponer de un sector público más

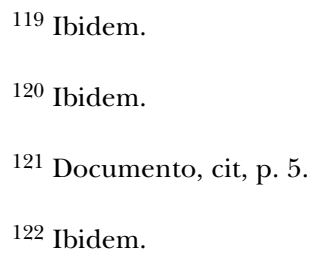


fuerte y con mayor capacidad. Lo importante es que el sector público cumpla su papel y que actúe con transparencia y responsabilidad al servicio objetivo del interés general. Por eso, es fundamental aprobar normas de contabilidad pública claras, revitalizar los mecanismos de control sobre el Gobierno y la Administración pública. En definitiva, lo decisivo es que el Gobierno cumpla su papel más relevante: la mejora continua de las condiciones de vida de los ciudadanos. En este sentido, y teniendo presentes las funciones básicas del gobierno, propusimos una escala de nuevos indicadores de resultados repartidos en tres niveles $(1,2$, y 3$)$.

En el nivel 1 se propuso medir los aspectos cualitativos del desempeño del Gobierno: la eficiencia y responsabilidad del sector público. En el nivel 2 se hizo referencia de dos nuevos indicadores: el funcionamiento del sistema electoral y político y el funcionamiento del sistema judicial. Por lo que se refiere al nivel 3 propusimos tres parámetros de medición: la descentralización de las actividades del sector público y la participación popular, la protección de la intimidad en la regulación del comercio electrónico y los mecanismos de protección para el sector financiero.

En el nivel 1, además se aconsejó la evaluación de las auditorías y la supervisión de presupuestos públicos. En el nivel 2, se llamó la atención sobre indicadores como pueden ser los mecanismos de rendición de cuentas, el promedio de tiempo que lleva aprobar la legislación en el parlamento, la existencia de un órgano de gestión electoral independiente con capacidad para convocar elecciones libres y limpias, la existencia de un sistema de inscripción de votantes accesible a todos o el número de votantes desglosado por género como porcentaje de los votantes inscritos. Esto por lo que se refiere al sistema electoral; en lo atinente al sistema judicial llamamos la atención sobre el número de casos pendientes y el número de casos resueltos, la calidad de las resoluciones judiciales medida por los errores de los tribunales de primera instancia y el porcentaje de fallos revocados en apelación, así como por el número de jueces sometidos a medidas disciplinarias. Por lo que se refiere al tercer nivel, el Comité sugirió que se considerasen también como indicadores: el porcentaje de los ingresos públicos totales asignados y gestionados a nivel regional o la existencia de mecanismos institucionalizados para celebrar consultas periódicas entre los Gobiernos locales y las organizaciones de la sociedad civil sobre políticas y programas de índole social y económica. Igualmente, en materia de protección de la intimidad puede ser de interés establecer un indicador de la legislación en el que se valoren ciertos parámetros: consentimiento, disposiciones de compensación y supervisión en relación con los mecanismos de aplicación coercitiva, disposiciones que permitan determinar 
con que fines una organización reúne información personal, disposiciones relativas al acceso de una persona a la información obtenida sobre ella y su capacidad de cuestionar y enmendar la información de que se trate y posibilidad de que el gobierno disponga de un programa activo para educar al público sobre protección de la intimidad $^{123}$. En materia de protección del sistema financiero, nos pareció fundamental que se midan los sistemas de garantías de depósitos.

El documento que estoy comentando finaliza con unas recomendaciones de "mínimos" a elevar al observatorio mundial del sector público. Son los siguientes: empleo público como porcentaje de la población, consumo público como porcentaje de la población, consumo público como porcentaje del PIB, gasto público central como porcentaje del PIB, gasto público central por tipo y función como porcentaje del gasto total del gobierno central, ingresos tributarios del gobierno central como porcentaje del PIB. Finalmente, se recomienda que se apruebe un nuevo indicador: disposiciones para realizar auditorías contables periódicas e independientes de los órganos gubernamentales y para estatales. También, para terminar, se pide al Comité que analice con mayor detenimiento el tema de los indicadores relacionando de los niveles 1 y 2 cualquier indicador que estime apropiado para su inclusión en el observatorio del sector público ${ }^{124}$.

\section{CONCLUSIONES DE LA REUNIÓN ANUAL DEL COMITÉ DE EXPERTOS (2003)}

En la reunión de 2003, trabajamos, como ha quedado señalado, sobre los documentos elaborados por la secretaría de la División de Economía y Administración pública de Naciones Unidas: ampliación de la capacidad de la Administración pública para aplicar la Declaración del Milenio, datos básicos sobre el sector público y actividades de Naciones Unidas en materia de Administración Pública. La conclusión general, que da precisamente título a la reunión de 2004, fue la "necesidad de revitalizar y revalidar la Administración pública para que el Estado pudiera desempeñar su papel en evolución a fin de servir mejor a los ciudadanos"125. Es decir, subrayar la dimensión cualitativa de

\footnotetext{
123 Documento, cit, p. 10.

124 Documento..., cit, p. 12.

125 Documento E/C. 16/2003/6, p.iii.
} 
la Administración pública en un modelo de Estado social y democrático de Derecho en el que los intereses generales ya no se definen única y unilateralmente por la Administración pública, sino en permanente contacto y cooperación con la realidad.

En este sentido, señalamos que un asunto de interés mundial que se plantea recurrentemente en todos los foros es el de la función fundamental de los sistemas e instituciones de gobierno para promover el desarrollo económico y social; aumentar el acceso a los servicios para la mayoría de los pobres y marginados; aplicar la legislación sobre derechos humanos; potenciar la participación de la mujer en el proceso de desarrollo y proteger la calidad del medio ambiente. Lógicamente, la tarea ingente de promover el desarrollo económico y social de las personas es, en mi opinión, el cometido central de las Administraciones públicas modernas. Me interesa destacar que hacemos referencia al término "promover" porque, a mi juicio, éste es el verbo que mejor define dinámicamente la principal función administrativa: hacer posible, facilitar el libre desarrollo de las personas en un orden social justo. El compromiso social de la Administración pública es obvio en la medida en que discurre en el Estado social y en la medida que todavía existentes lacerantes diferencias sociales que no se pueden proyectar sobre el acceso a los servicios públicos.

No se puede olvidar, en este sentido, que la relación entre Administración pública y derechos humanos es cada vez más directa puesto que, en efecto, los intereses generales en un Estado social y democrático de Derecho residen, en buena medida, en la promoción de todos y cada uno de los derechos humanos por parte de todos los ciudadanos. En esta visión del interés general más abierta y participativa hay que tener bien presente la función de la mujer, históricamente preterida, y que tanto enriquece una versión más plural y dinámica de los intereses públicos.

Otro asunto que hoy siempre se trata en sede de reformas administrativas y políticas públicas es la especial sensibilidad ecológica que puede permitir que la vida en el planeta sea más habitable y, sobre todo más humana.

En esta tarea es lógico que se busquen mayores y mejores alianzas entre la Comisión de Desarrollo Social del ECOSOC y nuestro Comité de Expertos, ya que hoy el desarrollo económico y social sigue siendo la principal tarea de la Administración, sobre todo en los países en desarrollo. en esta línea, hemos pedido al ECOSOC que dedique una reunión monográfica de alto nivel a es- 
tas cuestiones y que la Administración pública pase a ser "parte integrante del proceso de seguimiento de las decisiones de las conferencias"126.

En relación con el Programa de N.U. en materia de Administración y Finanzas públicas, recomendamos que la Secretaría vaya prestando asesoramiento técnico a los Estados miembros en lo que se refiere a la mejora de la preparación y cualificación del personal del sector público, al fortalecimiento de sistemas e instituciones de Gobierno y Administración pública, al fomento de la transparencia y la gestión responsable y facilitando ayuda a la reconstrucción del sector público cuando fuera necesario ${ }^{127}$. Como fruto del debate sobre la sociedad del conocimiento y la Administración pública, le pedimos a la Secretaría que estudie mejor el papel del Estado como facilitador y usuario de conocimientos y nuevas tecnologías para estimular la innovación y que continúe su labor en el ámbito de los datos básicos sobre el sector público ampliando paulatinamente el número de indicadores, con especial referencia a la eficacia, la transparencia y la participación en la labor de Gobierno.

La metodología es necesaria para la elaboración de las conclusiones y recomendaciones de los trabajos de nuestro Comité. Se centró en unas reflexiones generales, unas recomendaciones que requieren la adopción de medidas por el Consejo Económico y Social y unas recomendaciones sometidas a la consideración del Consejo Económico y Social. Además, hicimos un conjunto de comentarios a los documentos presentados por la Secretaría: estrategias para dotar al sector público de funcionarios con un alto nivel de competencia, situación y tendencias del desarrollo del gobierno electrónico y, función de la Administración pública en la incorporación de las estrategias de lucha contra la pobreza en los objetivos de desarrollo del milenio y dichos básicos sobre el sector público. Y, para terminar, unas reflexiones sobre el Programa de N.U. en materia de Administración y Finanzas públicas y unas ideas sobre la futura labor del comité de Expertos en Administración Pública. Vayamos por partes.

En relación con los objetivos de desarrollo de la Declaración del Milenio, pensamos que el Estado es esencial para alcanzar los objetivos públicos y garantizar el interés público entendido como la atención a las necesidades de

\footnotetext{
126 Documento, cit, p. iii..

127 Documento..., cit, p. 3
} 
los ciudadanos y las comunidades y a la protección de los derechos individuales ${ }^{128}$. Conceptos, como se puede deducir fácilmente, que se basan en los postulados del pensamiento abierto, dinámico, plural y complementario. El Estado y las instituciones públicas son los elementos fundamentales "ya que en ellos recae la responsabilidad última de que estén atendidas las necesidades básicas de los ciudadanos" ${ }^{129}$, afirmación con la que pretendemos señalar que la función básica de la institución pública por excelencia es irrenunciable. Lo cual no quiere decir, ni mucho menos, que esta tarea se realiza de forma exclusiva y excluyente por el Estado. En este sentido, pensamos que para alcanzar los objetivos del Milenio en relación con los servicios públicos y la pobreza, es necesaria "una Administración pública de calidad, eficiente y responsable en un marco, obviamente democrático" ${ }^{130}$. La calidad, la eficiencia y la responsabilidad son tres características de los procesos de reforma y modernización de la Administración pública realizados en los principales países del mundo en un contexto de creciente y objetivo servicio al interés general.

Por lo que se refiere a la posición de la Administración pública en relación con la economía, nos parece que "con una política eficaz, el Estado y la Administración pública tienen más capacidad de favorecer un entorno propicio para lograr un mercado más potente y una sociedad mejor"131. Es decir, el Estado tiene una función promocional que incluye al mercado y a las condiciones sociales. Por ello, el Estado y la Administración pública deben garantizar las reglas que permitan un desarrollo razonable y equilibrado del mercado y, asimismo, deben hacer posibles unas condiciones en la sociedad que faciliten el libre desarrollo de las personas en un marco de justicia y solidaridad que salvaguarde, siempre y en todo caso, la dignidad del ser humano.

Desde el punto de vista de la dimensión del aparato público y del gasto público realizado para mantener las estructuras administrativas, pensamos que, a la vista de la realidad, "es necesario definir mejor los requisitos que exige el correcto funcionamiento de las estructuras públicas"132, como puede ser

\footnotetext{
${ }^{128}$ Ibidem.

${ }^{129}$ Ibidem.

${ }^{130}$ Ibidem.

${ }^{131}$ Ibidem.

${ }^{132}$ Documento..., cit, p.p. 3-4.
} 
el caso del gasto público en proporción al PIB ya que, en muchos supuestos, la calidad de los servicios públicos no es, ni mucho menos proporcional al gasto público empleado en dichos servicios.

La cuestión no se centra únicamente en el sujeto que presta o facilita los servicios públicos sino que es imprescindible fomentar la participación de los ciudadanos a través de políticas descentralizadoras, revitalizar la responsabilidad de todos los sectores sociales, más información y adoptar decisiones fundamentadas en todos los niveles de la ciudadanía y de las comunidades ${ }^{133}$. Llamo la atención sobre la expresión "fundamentadas" porque no debe pasar desapercibido para el lector del Documento que ahora glosamos, que la motivación de la actuación administrativa es una señal de modernización y, lo que es más importante, es una exigencia del sistema democrático en relación con la Administración pública. Además, nos parece que hoy "la buena gestión de los asuntos públicos consiste en una colaboración efectiva entre los sectores público y privado y la sociedad civil, y que cada ámbito necesitaba la justa proporción del personal más cualificado"134.

Este es un punto ciertamente central para el Comité. Tan es así que nos inclinamos porque la colaboración, entre Estado, sector privado y sociedad civil es fundamental para disponer de una Administración pública sólida ${ }^{135}$. En este sentido, soy de los que pienso que esta perspectiva complementaria entre lo público y lo privado viene casi impuesta por la realidad y por la fuerza del pensamiento abierto, plural, dinámico y, por supuesto, complementario. Por ello, recomendamos vivamente relaciones más eficaces entre la dimensión pública y privada porque hoy la participación es vital para el desarrollo económico y social y porque, en el marco de las políticas públicas actuales, la gobernabilidad o gobernación democrática debe "comprender mejor el modo de sumar fuerzas y facilitar una mayor coordinación entre las actividades del sector público, el sector privado y la sociedad civil ${ }^{136}$.

En términos generales, las instituciones públicas han sido, son y serán cruciales para "promover el desarrollo económico, aumentar el acceso a los ser-

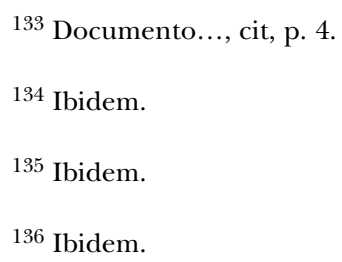


vicios para la gran mayoría de los pobres, poner en vigor la legislación sobre derechos humanos, elevar la participación de la mujer en el proceso de desarrollo y proteger la calidad del medio ambiente" 137 . En nuestro informe, queremos dejar sentada la función "promocional" de los poderes públicos en relación con el desarrollo económico y social, y en relación con algunos de los objetivos del Milenio. La función "promocional" de las instituciones públicas consiste, en mi opinión, en poner los medios para que se produzca, en un contexto de libertad solidaria, el acceso a los servicios de quienes están marginados, la participación real de la mujer o una mayor sensibilidad, con efectos prácticos, de la dimensión ecológica. Lo fundamental es que la Administración pública sea más consciente de que ya no puede, ni debe, configurar única y totalitariamente el interés general. Ahora, la función "esencial" del Estado y de las instituciones públicas es garantizar las libertades y derechos de los ciudadanos en un contexto de promoción del interés general.

Reconociendo que en los últimos tiempos hay una mayor preocupación por mejorar la calidad y eficacia de la labor del Gobierno y de la Administración pública en todos los Estados en todas las conferencias y cumbres de las Naciones Unidas, es preciso "revitalizar y revalidar la Administración pública" para que el Estado pueda desempeñar su papel en evolución a fin de servir mejor a los ciudadanos" ${ }^{138}$ cuestión que pensamos que debe tenerse en cuenta tanto en los países en desarrollo como en los desarrollados. Revitalizar quiere decir subrayar y fortalecer el sentido vital del Estado. Por eso, nos pareció conveniente conectar esta tarea con el fortalecimiento institucional y "la instrumentalidad del Estado". Ciertamente el Estado se justifica en la medida en que atienda a las necesidades públicas de la gente y, por ello, es menester en este tema vincular el sentido instrumental del Estado al logro de los objetivos del Milenio. Revalidar puede querer decir dar mayor valor a lo público desde una perspectiva abierta del interés general y desde planteamientos que supongan renovar y subrayar la caracterización ética, permanentemente presente en el trabajo al servicio del sector público: servicio, objetividad, imparcialidad, integridad, eficacia, eficiencia, sensibilidad social... También debe llamarse la atención sobre el sentido con el que planteamos la relevancia de la revitalización y revalidación del aparato público: " a fin de servir mejor a los ciudadanos". Por tanto, el servicio a los ciudadanos se exige en el concepto central de la Administración pública. Es conveniente señalar algo obvio: no ha

${ }^{137}$ Ibidem.

${ }^{138}$ Documento..., cit, p. 5. 
cambiado el papel clásico de la Administración pública, sino que se revitaliza y revalida.

En el Comité pensamos que esta revitalización y revalidación trae consigo dos importantes tareas pendientes. Primera, proyectar este compromiso en los ámbitos locales y nacionales para que fructifique la labor en pro de los objetivos de desarrollo del Milenio ${ }^{139}$. Segunda, mejorar la capacidad de proteger a los ciudadanos contra los riesgos sociales y promover políticas dirigidas a la igualdad de oportunidades para todos los ciudadanos, particularmente a los más vulnerables: niños y ancianos ${ }^{140}$. Funciones, ambas que reflejan la profunda dimensión social que tiene la Administración pública que, hoy, insisto debe realizar en el marco de lo postulados del pensamiento abierto, plural, dinámico y complementario.

Los Estados compuestos, sean federales, regionales o autonómicos, deben involucrar a loa diferentes entes territoriales en los objetivos del Milenio; en especial recomendamos a las Naciones Unidad que dialoguen "con diferentes países para promover los objetivos de desarrollo del Milenio como parte de una campaña nacional de buena gestión de los asuntos públicos para avanzar hacia un Estado fuerte y una cultura de aprendizaje"141. La promoción de una buena gestión pública está muy relacionada con la preparación, formación y capacidad del personal que trabaja en el sector público, por lo que, desde el Comité de Expertos, reclamamos que la capacitación se fortalezca ya que es imprescindible para alcanzar los objetivos del Milenio. En esta dirección, propusimos la "definición de un cuadro superior de funcionarios públicos, competente y responsable, que debería renovarse en parte, a intervalos periódicos, según criterios basados en los méritos ${ }^{142}$. Por otra parte, planteamos la necesidad de incrementar los presupuestos destinados a la capacitación y perfeccionamiento de las tareas de dirección y gestión y, del personal, en general ${ }^{143}$. Quienes hemos dedicado tiempo a la formación de funcionarios -en mi caso más de diez años- sabemos bien la importancia que tiene esta función y la relación tan directa que existe entre capacitación y calidad en la prestación de los servicios públicos.

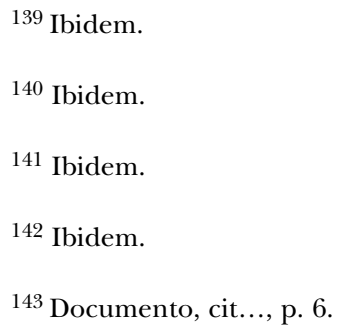


Además de manifestar apoyo y colaboración al proceso de fortalecimiento del Estado en el continente africano -uno de los principales objetivos de la División de la Economía y Administración pública de ECOSOC-, pensamos que está en la médula de la revitalización de la función pública la batalla por recuperar su orgullo y su dignidad, por lo que es necesario disponer de retribuciones apropiadas para los servidores públicos ${ }^{144}$. En este sentido, se propuso que se aproveche para ello el 23 de junio, día de las Administraciones Públicas de las Naciones Unidas, y los premios de Administración pública. Conseguir que la ciudadanía perciba que el trabajo al servicio del sector público goza de prestigio social y que contribuye eficazmente al progreso de un país, pasa necesariamente por el compromiso cotidiano de los funcionarios públicos con los valores del servicio público y, especialmente, con la solidaridad y la voluntad de lograr la igualdad de derechos ${ }^{145}$.

Las relaciones entre política y administración hacen necesaria una permanente tarea encaminada a la profesionalización de la función pública que permita la continuidad de las políticas públicas que hacen posible el desarrollo de un país. Si no hay función pública profesionalizada, entonces el "spoil-system" impedirá el desarrollo y la función pública no será más que un apéndice continuo y un botín que conquistan los ganadores de las elecciones. Ahora bien, en el Comité hemos querido señalar, me parece, que siendo la profesionalización una característica de la función pública, la función pública reclama "profesionalidad" en quién la practica y, así, los valores o principios del interés público, erradicación de la pobreza, igualdad, derechos individuales, transparencia, responsabilidad, eficiencia, deben ser comunes a ambos estamentos política y función pública.

La existencia de diferentes tradiciones y modelos de función pública aconseja que se disponga de algún estudio sobre los perfiles político-administrativos existentes, tarea que hemos pedido a la Secretaría de Naciones Unidas que nos acoge ${ }^{146}$.

En materia de gobierno electrónico, pensamos que es posible "lograr una Administración pública más accesible y, sobre todo, más responsable, si los re-

\footnotetext{
144 Ibidem.

145 Ibidem.

146 Ibidem.
} 
cursos del gobierno electrónico se aplican de una forma más integral y tras un análisis a fondo de las condiciones concretas del país" ${ }^{147}$, y siempre que se fomente la trasparencia y la ciudadanía compruebe que su uso mejora sus condiciones de vida y sus posibilidades de participación.

Tras terminar las reflexiones generales, pasamos a formular algunas recomendaciones que precisan la adopción de medidas por el Consejo Económico y Social. En concreto, el Comité de Expertos recomendó que el tema de la revitalización de la Administración Pública sea el tema central de la Comisión de Expertos en la próxima reunión de 2004. Así ha sido: el encuentro de este año 2004 tiene como temas centrales: la revitalización de la Administración pública, la capacidad institucional del sector público para la renovación de África, los datos básicos sobre le sector público y el examen y análisis del programa de Naciones Unidas en materia de Administración y Finanzas Públicas. También es preciso que exista una mayor armonía y vinculación entre nuestro Comité y la Comisión de Desarrollo Social de ECOSOC y que se trabaje en este tema el seno de las conferencias sobre le Gobierno y la Administración pública ${ }^{148}$.

Por lo que se refiere a las recomendaciones que dirigimos a los diferentes gobiernos, destacarían los siguientes. Primera, es necesario establecer o reforzar los sistemas y dependencias de planificación y gestión de personal y fortalecer la capacidad de dirección de los dirigentes futuros y los actuales. Segunda, es menester profesionalizar la función pública y establecer estructuras eficaces de incentivos para fomentar el reconocimiento y el orgullo profesional de la función pública. Tercera, aprovechan los actos del día de la Administración pública de Naciones Unidas (23 de junio) para mejorar la imagen que se tiene del sector público, demostrar reconocimiento por la tarea de los funcionarios públicos y animar a los jóvenes a emprender con orgullo su carrera en este sector. Cuarto, establecer organizaciones con cultura de aprendizaje en la función pública y recurrir al potencial humano de los grupos menos representados. Y, finalmente en quinto lugar, que los dirigentes públicos aprovechen el gobierno electrónico para prestar servicios de forma más rápida y eficaz, más transparentes, más participativos, con especial referencia a la protección de los derechos a la intimidad y a la protección jurídica cuando establezcan sistemas de gobierno electrónico ${ }^{149}$.

\footnotetext{
147 Ver Documento, cit, p.p. 8-9.

148 Documento, cit, p.p. 11-12.

${ }^{149}$ Documento, cit..., p. 13.
} 
También se formularon algunas recomendaciones al sistemas de Naciones Unidas, que sintetizo con brevedad. Divulgar los trabajos del Departamento de Asuntos Económicos y Sociales de la Secretaría General en el ámbito de la Administración pública, solicitar una declaración de Secretaría General con motivo del día de la Administración pública de Naciones Unidas, mantener la labor normativa y de asistencia técnica de la Secretaría General, continuar con el World Public Sector Report traduciéndose a más idiomas, investigar en el marco de la Secretaría General sobre políticas para desarrollar la capacidad humana del sector público en los países en desarrollo, ampliar la red en línea (UNPAN) a los ámbitos regionales y locales, preparar y difundir por la Secretaría General instrumentos y directrices para mejorar la capacidad de planificación y gestión de los recursos humanos en los países en desarrollo (cartas regionales de Administración pública y manuales sobre códigos de conducta), organización por la Secretaría General a nivel regional (África, mundo árabe, América latina, Asia, Pacífico, Europa Central y Oriente) y en pequeños Estados sobre posibilidades para fortalecer la capacidad de los recursos humanos en el sector público aplicado a países en desarrollo; seguir prestando por la Secretaría General asesoramiento técnico para mejorar la capacitación del personal público para reforzar los sistemas e instituciones de Gobierno y Administración pública, para fomentar la transparencia y la responsabilidad y para reconstruir la Administración pública en países bajo conflictos o en situación de descentralización; intensificar (Secretaría General) las actividades de capacitación para funcionarios, con especial referencia a África; realizar los trabajos (Secretaría General) necesarios para analizar y delimitar mejor el papel del Estado como propiciador y como usuario de conocimiento y tecnología a fin de apoyar la innovación en todos los niveles de la Administración pública; financiar el gobierno electrónico (Secretaría General) y facilitar mecanismos para poner en marcha infraestructuras de aprendizaje; aplicar el gobierno electrónico en la reducción de la pobreza (Secretaría General); publicando con periodicidad anual el estudio mundial sobre Gobierno electrónico; prestar asistencia técnica para integrar los objetivos del Milenio en el espacio de la política nacional (Departamento de Asuntos Económicos y Sociales) y asesorar en materia de gobierno compartido; adoptar las medidas necesarias para que se potencien las actividades regionales a favor de los objetivos de desarrollo del Milenio (Departamento de Asuntos Económicos y Sociales); evaluar sistemáticamente las necesidades de la capacidad institucional del África subsahariana (Secretaría General) y elaboran un repertorio general de experiencias y prácticas recomendables en Administración pública; institucionalizar el grupo de trabajo sobre datos básicos del sector público para que la Secretaría general siga trabajando en la labor de seleccionar un conjunto concreto de indicadores sobre el sector público, teniendo pre- 
sente tres aspectos de la evaluación del sector público: eficiencia, transparencia y participación ${ }^{150}$.

En la reunión de 2003, los temas sobre los que trabajamos, como ya se ha señalado, fueron: estrategias para dotar al sector público de funcionarios con un alto nivel de competencia, situación y tendencias del desarrollo del Gobierno electrónico, el papel de la Administración pública en la lucha contra la pobreza, los datos básicos sobre el sector público y las actividades del Programa de las Naciones Unidas en materia de Administración Pública.

Por lo que se refiere a la competencia de los funcionarios, a partir del informe presentado por la Secretaría, ya analizado, expresamos nuestro criterio tendente a que el sector público disponga de una buena proporción de buenos funcionarios. También pensamos que es preciso combatir la pésima imagen que a veces acompaña en algunos países al sector público en las prácticas de clientelismo donde existan. En este sentido nos parece que los responsables de las políticas de función pública de los diferentes países "deben examinar críticamente los sistemas de selección del capital humano en el sector público y formular estrategias a largo plazo para invertir este tendencia”. En nuestra opinión los esfuerzos para mejorar la preparación y competencia de los funcionarios debe centrarse en cuatro áreas: dedicación, rectitud de los directivos públicos, análisis y formulación de políticas como resultado de un proceso congruente de recogida de información y de consultas, profesionalidad y responsabilidad de los directivos básicos para la prestación de los servicios públicos ${ }^{151}$, la mejora de la competencia profesional de los funcionarios debe plantearse, en nuestra opinión, en un marco institucional sólido ${ }^{152}$, en un entorno de buena gestión de los asuntos públicos y teniendo siempre presente la necesidad de adoptar estrategias a largo plazo sobre aspectos relevantes como pueden ser la carrera administrativa, los sistemas de gestión y planificación del personal, la profesionalización de la función pública, la recuperación del prestigio de lo público $^{153}$, la creación de una cultura de aprendizaje permanente o el aprovechamiento del capital humano de los grupos menos representados ${ }^{154}$.

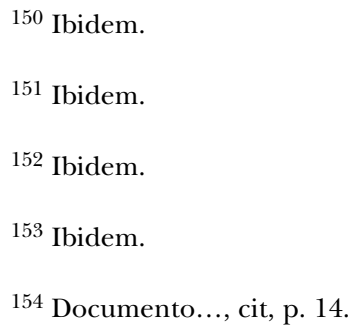


Especial referencia, y especial trascendencia tiene recuperar o establecer el orgullo de trabajar al servicio del sector público. Esta es quizás la cuestión teórica más importante para que la Administración cumpla cabalmente su función. Por eso, subrayar este tema nos parece central porque "los países que valoran el sector público tienen muchas más facilidad para contratar y retener a funcionarios con un alto nivel de competencia y para inculcar un sentimiento de orgullo con el sector público"155. Para ello, nada mejor que asegurar que los principios de publicidad y concurrencia presidan el régimen de la contratación pública, y nada mejor que los principios de mérito y capacidad presidan el régimen de la relación y promoción del personal.

En esta materia, desde el Comité hemos llamado la atención sobre la importancia de las retribuciones dignas en orden a mejorar el sistemas de función pública. Asimismo, nos parece que "el fortalecimiento de la capacidad de dirección debía ocupar un lugar privilegiado en las actividades de desarrollo, y que debían establecerse estrechas relaciones de colaboración y asociación para ayudar a los países en desarrollo a afianzar su capacidad de dirección en el sector público" 156 . Tarea, la de la función directiva que, a nuestro parecer, debe estar orientada a la protección del interés público definido en consulta con los ciudadanos, a la promoción de una cultura ética y al fomento de la capacidad de gestión estratégica ${ }^{157}$.

Por lo que se refiere a la situación y tendencias del desarrollo del Gobierno electrónico, el Comité estudió el documento "ad hoc" suministrado por la Secretaría. En nuestras deliberaciones, señalamos la gran importancia del papel del Gobierno en esta materia, en la que se puede "reorganizar su funcionamiento a fin de fomentar el sentido de ciudadanía y educar al público sobre las complejas cuestiones del Estado"158, que el gobierno fomente la rendición de cuentas por parte de los funcionarios y la mejora de la transparencia administrativa. En otro orden de cuestiones, nos parece importante recordar las funciones del Gobierno electrónico: informar a los ciudadanos, facilitar un trabajo más eficaz y fomentar la participación; tareas que se deben

\footnotetext{
155 Ibidem.

${ }^{156}$ Documento..., cit, p. 15.

157 Ibidem.

${ }^{158}$ Documento..., cit, p .16.
} 
fortalecer, a la vez que hay que evitar la debilidad institucional y la limitación de los conocimientos prácticos ${ }^{159}$. También nos parece que en esta tarea hay que tener presente la diferente realidad social y económica de los países y, en todo caso, exigir que se comience efectivamente como un instrumento fundamental para el desarrollo económico, la reducción de la pobreza y para que las "personas puedan desarrollarse con mayor libertad en la sociedad"160.

Precisamente en materia de reducción de la pobreza y la Administración Pública, en el marco del documento elaborado por la Secretaría, ya glosado, nos parece que existen grandes dificultades para cumplir, en esta materia, los objetivos de la Declaración del Milenio. Por una parte, porque muchos países no disponen de sociedades civiles sólidas que se puedan movilizar para alcanzar dichos objetivos. Y, por otra parte, porque en este momento existe un desfase entre los objetivos propuestos y los procesos necesarios para alcanzarlos por lo que es prioritario apoyar a los Gobiernos nacionales en esta tarea ${ }^{161}$. En esta línea, pensamos que la cooperación Sur - Sur y Norte - Sur es un buen medio para ayudar al sistema de Naciones Unidas a que contribuya a "que los Gobiernos nacionales pueden poner al día su capacidad de Administración pública a fin de alcanzar los objetivos de la Declaración del Milenio"162. No se puede olvidar en este punto el gran potencial que tiene la descentralización que, a nuestro juicio, no solo promueve los principios democráticos en el ámbito subnacional, sino también la erradicación de la pobreza.

El documento acerca de los "datos básicos sobre le sector público" también fue objeto de estudio y análisis por nuestro Comité de Expertos. En concreto, sobre la propuesta de la Secretaría, ya comentada, de ampliar los parámetros, somos conscientes de que el tema de los indicadores se refiere a crear la capacidad para estimar los valores de estos indicadores con un nivel de precisión satisfactorio ${ }^{163}$. Además, debemos ser conscientes de que evaluar el sector público siempre es complejo por lo que, en cualquier caso, nos parece que es imprescindible disponer de los datos sobre los costos unitarios de los

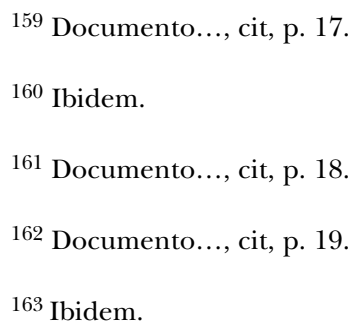


diferentes servicios prestados por las Administraciones públicas, así como el grado de participación de la sociedad en las estructuras deliberantes. Finalmente, le hemos pedido al Departamento de Asuntos Económicos y Sociales de la Secretaría que analice los datos relativos a los recursos asignados en los ámbitos regional y local ${ }^{164}$.

En relación con el Programa de Naciones Unidas las materias de Administración Pública expresamos nuestro beneplácito por las tareas realizadas y los logros obtenidos. Aún así, nos parece que estas "iniciativas no habían tenido suficiente repercusión pública en el mundo", por lo que es pertinente impulsar la difusión de estas actividades, incluida, claro está, el día de la Administración Pública de Naciones Unidas ${ }^{165}$. En todas estas tareas es menester, me parece, primar la metodología intersectorial y procurar una mejor coordinación, a cuyo fin habría que pensar en la potencialidad del Gobierno electrónico y, por ello, prestar asistencia técnica precisamente en esta materia ${ }^{166}$. También se debe cuidar el intercambio de experiencias, para lo cual solicitamos que se elaboren más catálogos y repertorios de las mejores prácticas en la Administración pública; felicitamos a la División de Administración y Economía pública por la puesta en marcha de la red UNPAN, iniciativa dirigida precisamente al intercambio de información y de prácticas. Igualmente, felicitamos al Departamento de Asuntos Económicos y Sociales de la Secretaría por promover los principios y valores fundamentales asumidos por el Consejo Económico y Social y por formular y aplicar programas que contribuyan al logro de los objetivos del Milenio ${ }^{167 .}$

Por terminar, unas reflexiones sobre la futura labor de nuestro Comité de Expertos. Pensamos que nuestra función es triple. Primera, detectar las nuevas cuestiones que se plantearan en el ámbito de la Administración pública y sus consecuencias normativas para los Estados miembros y formular recomendaciones sobre funciones y valores relativos a la participación de la Administración Pública en el proceso de desarrollo que contribuirán a las decisiones normativas adoptadas por el Consejo Económico y Social. Segunda, proporcionar orientación normativa y recomendaciones operativas a los Esta-

\footnotetext{
${ }^{164}$ Documento..., cit, p. 20.

165 Ibidem.

${ }^{166}$ Documento..., cit, p. 21

${ }^{167}$ Documento..., cit, p. 21.
} 
dos miembros sobre el modo de abordar cuestiones fundamentales relativas al funcionamiento del Estado, en particular en su labor para cumplir la Declaración del Milenio y los compromisos asumidos en las conferencias mundiales de las Naciones Unidas. Y, tercera, orientar la labor del sistema de Naciones Unidas respecto a la Administración pública examinando los programas y proponiendo directrices concretas para sus actividades.

Propusimos el tema de la reunión de 2004: la revitalización de la Administración Pública, que fue aceptado. Decidimos prestar especial atención a las necesidades de África en materia de capacidad institucional. Y, además, señalamos que pese a la variedad de modelos, de culturas y de tradiciones, es preciso "determinar los elementos comunes estudiando las diferentes tradiciones existentes en lo referente al estilo de organización y entrando en sintonía con las necesidades de las personas de distintas partes del mundo a fin de fortalecer un espíritu multilateral renovado" 168.

finalmente, estamos decididos a abordar la cuestión de los valores de la Administración pública plasmándolos en una serie de grandes principios o carta en que se definieran los principales criterios que permitan al Estado promover la democracia y el desarrollo económico, así como la función de todas las partes que se ocupan del interés público".

\section{LA REVITALIZACIÓN DE LA ADMINISTRACIÓN PÚBLICA CO- MO UNA MEDIDA ESTRATÉGICA PARA EL DESARROLLO HU- MANO SOSTENIBLE}

La reunión del Comité de Expertos de 2004, conforme a lo establecido, analizó varios documentos elaborados por la Secretaría. Este año, con la interesante novedad de que, junto al expositor oficial de N.U., un miembro del Comité, o Comisión comentaría cada documento en cuestión.

El primero de los documentos a analizar es el que lleva como rúbrica "La revitalización de la Administración pública como una medida estratégica para el desarrollo humano sostenible: perspectiva general"169. Es el documento

\footnotetext{
${ }^{168} \mathrm{E} / \mathrm{C} 16 / 2004 / 2$.

169 Documento, cit, p. 1.
} 
central de la reunión, pues los demás, salvo los específicos que se refieren a África y a los datos del sector público, no son más que derivaciones de éste.

El documento comienza con el recordatorio de la función básica de la Administración pública: "que la gestión de asuntos públicos promueva el interés general" ${ }^{170}$. A continuación, y con un cierto tinte crítico, llama la atención la sustitución del término "Administración pública" por el de "Gestión pública”, que achaca a la influencia de los enfoques economicistas sobre la reforma administrativa y, especialmente, al énfasis que se puso en conceptos como: fuerza del mercado, desregulación, eficiencia y ahorro en el sector públi$\mathrm{co}^{171}$. Incluso se reconoce que esta perspectiva pudo minar las misiones tradicionales del Estado y producir deficiencias que hayan debido sufrir los grupos más vulnerables en lo que se refiere a la educación, sanidad o en lo atinente a la función de seguridad del Estado ${ }^{172}$. En fin, "procurando con demasiado celo adoptar comportamientos propios de la gestión de empresas privadas, el sector público quizás se haya apartado de su responsabilidad de atender el interés público general en varios aspectos" ${ }^{173}$. El documento, pues, con prudencia, como es lógico, certifica algo que muchos hemos pensado y registrado por escrito: el ocaso de la Administración pública en nuestro tiempo, con excepciones, tiene mucho que ver con la pretendida superioridad de lo económico sobre estas consideraciones, como pueden ser las dimensiones cualificadas del desarrollo social de los pueblos y, sobre todo de las personas. En este sentido, no se debe olvidar que el sentido central de la existencia de la Administración pública no es otro que contribuir a la mejora del bienestar integral de los ciudadanos.

Como consecuencia de esta cierta languidez en que parece haber entrado la Administración pública aparece la emergencia de una idea de la gobernanza que postula la participación, el interés del pueblo, la equidad, la transparencia y la rendición de cuentas en los asuntos públicos"174. Paralelo a esta

\footnotetext{
${ }^{170}$ Ibidem.

${ }^{171}$ Documento, cit, p. 2.

172 Ibidem.

${ }^{173}$ Ibidem.

${ }^{174}$ Ibidem.
} 
atinada dimensión de la gobernanza, "hace falta dar mero impulso a la Administración pública a fin de que sus actividades de gestión de los asuntos públicos vuelvan a estar centradas en las funciones primordiales del Estado y en la defensa del interés público general”" ${ }^{\prime 75}$.

Probablemente, la vuelta a los fines propios de la Administración pública que es, no es ni mucho menos, incompatible con una nueva gobernanza tal y como plantea la Secretaría en el documento que estamos glosando. Sería un error, y grave, plantear en términos de confrontación esta situación porque, en la realidad, el pensamiento abierto, plural, dinámico y complementario también ofrece soluciones interesantes. Por eso, la tarea revitalizadora, de nueva vida, de la Administración pública debe enmarcarse en esta perspectiva.

Antes de entrar en el comentario de los aspectos que el documento nos propone para la tarea revitalizadora es menester señalar, desde mi punto de vista, que la revitalización requiere una voluntad política firme e inequívoca de los dirigentes y debe basarse en la recuperación del prestigio social de la función pública. Si el estamento político no apuesta claramente porque la Administración pública contribuya efectivamente a la mejora de las condiciones de vida de los ciudadanos, no hay nada que hacer. Y, si la sociedad no percibe que la función administrativa goza de prestigio, por la categoría que debe predicarse del trabajo de los funcionarios públicos, pienso que la revitalización no cumplirá sus apetecidos frutos.

Desde otro punto de vista, y como jurista que soy, pienso que la revitalización de la Administración pública está por venir, por una razón para mí elemental. La llamada "huida del Derecho Administrativo" que caracterizó la conversión, a veces radical, de la propia Administración, y sus agentes, a la eficiencia y a la economía, hoy ha terminado por la sencilla razón de que el Estado, a través de su esencial papel de garantizador del interés general, tiene una evidente presencia en, por ejemplo, los llamados servicios de interés general. Es decir, vuelve el Derecho Administrativo, eso sí, a través de nuevos conceptos, instituciones o categorías del tiempo presente.

¿Cuáles son los puntos de referencia para la revitalización de la Administración pública? En opinión del documento, serían los siguientes:

175 Ibidem. 
1.- La redefinición y reafirmación de las funciones fundamentales del Estado, incluida la misión de garantizar la paz, la seguridad y la estabilidad, el Estado de Derecho y el orden, y crear un entorno propicio y sostenible para la iniciativa individual y del sector privado y el crecimiento económico y el desarrollo humano ${ }^{176}$. En esencia, subrayar el papel central de la Administración pública: la mejora de las condiciones de vida de los ciudadanos.

2.- Formación y mantenimiento de alianzas y colaboración entre las instituciones del sector público, la sociedad civil y el sector privado ${ }^{177}$ : Este es un punto esencial porque, en términos generales, se puede decir que hoy el interés general público, como en reiteradas ocasiones lo califica el documento, ya no se define unilateralmente por la Administración pública sino que, bien al contrario, desde un enfoque abierto y plural, se debe contemplar a partir de la vitalidad de la realidad en la que la sociedad tiene mucho que aportar.

3.- Fomento de la cooperación entre las instituciones del Estado y la Administración pública de diferentes países, a fin de facilitar el intercambio de experiencias positivas de renovación de la Administración pública ${ }^{178}$. Otra materia susceptible de revitalización es, claro que si, la colaboración en el conocimiento de las políticas públicas concretas que producen los beneficios buscados.

4.- Integración selectiva de principios y prácticas de gestión pública y gobernanza en la Administración pública, a fin de generar y promover sistemas de Administración públicas que sean eficientes, económicos y eficaces, además de participativos, flexibles, equitativos y responsables ante el público ${ }^{179}$. En este sentido, debe combinarse le eficiencia social y la eficiencia económica que, aunque no lo parezca, no son contradictorios y, ambos, deben presidir, en términos de compatibilidad, el trabajo de la Administración pública.

5.- Introducción, en la esfera de la Administración pública, de estructuras y de una cultura de la investigación, incluida la aplicación de nuevas tecnologías de la información y de las comunicaciones, que pueden ser fundamenta-

\footnotetext{
${ }^{176}$ Ibidem.

${ }^{177}$ Ibidem.

${ }^{178}$ Ibidem.

${ }^{179}$ Ibidem.
} 
les para dar nuevo impulso a la Administración pública ${ }^{180}$. Ciertamente, entre los criterios a implantar en el trabajo de los directivos públicos está el de la investigación en el sentido de transmitir, y adquirir, los hábitos precisos para tener una predisposición a analizar y examinar el porqué de lo que sale mal o de lo que sale bien.

6.- Atracción y retención en el sector público de los mejores recursos humanos $^{181}$. Para esto, es fundamental recuperar, o crear si es el caso, el prestigio de la función pública y, con muchas razones y sistemas de carrera y profesionalidad, hacer atractiva para "los mejores" el trabajo al servicio de la Administración pública.

La revitalización de la Administración pública tiene mucho que ver con la función del Estado en las políticas públicas y el desarrollo socioeconómico. Para mí, la tarea revitalizadora en este punto está conectada a la necesidad de que el "interés público general" se abra a la realidad y la propia sociedad tenga una parte relevante en la formulación, implementación y evaluación de las políticas públicas; así como a participar en los objetivos de desarrollo económico desde un punto de vista general y dinámico.

En relación con la participación social en la nueva gobernanza debe tenerse presente, así lo hice constar reiteradamente en las sesiones del comité, que una cosa es la participación libre y otra la participación dirigida. En efecto, la revitalización requiere la participación libre, no la participación que genere el poder que, en tantas ocasiones, no es más que más control social.

Nueva vida a la Administración supone, también, que el impulso reformista y modernizador se verifique desde la realidad, a partir de experiencias que hayan funcionado, dando igual que sean del pasado o no; lo importante es que ayuden a cumplir la función esencial de la Administración pública: mejorar las condiciones de vida de los ciudadanos.

Finalmente, debe citarse en el marco de las políticas de revitalización y revalidación de la Administración pública, que la descentralización no es la panacea que lo soluciona todo. Aún reconociendo que puede ser eficaz, se trata

\footnotetext{
180 Ibidem.

181 Vid. Documento E/C. 16/2004/3.
} 
de analizar caso por caso y, en función de las capacidades públicas para el bienestar integral de los ciudadanos, tomar las decisiones que correspondan.

\section{EL PAPEL DE LOS RECURSOS HUMANOS EN LA REVITALIZA- CIÓN DE LA ADMINISTRACIÓN PÚBLICA ${ }^{182}$}

No por obvio debe dejar de resaltarse que las personas, los funcionarios, son los agentes de la reforma y renovación de la Administración y, por tanto, el centro de su revitalización. Como señala el documento "los conocimientos, la aptitud, los valores y las actitudes de los funcionarios son cruciales para la eficacia del Estado"183.

Siendo, como es, esencial el papel del personal, hemos de subrayar que la relevancia de los recursos humanos debe estar orientada a la evaluación del rendimiento. De nada servirá apostar por una mejor capacitación del personal sino se integrara en los objetivos de la organización, muy en especial, de la demanda de servicios por parte de los ciudadanos. "A su vez, las metas, las prioridades y el rendimiento esperado de una organización no se pueden determinar sin tener en cuenta el marco más amplio de los objetivos nacionales y de política del Gobierno y el contexto socioeconómico general" ${ }^{184}$. Se trata, pues, de un enfoque complementario en el que todos: funcionarios y Gobiernos deben trabajar en la misma dirección. En este punto la integración entre la preparación del funcionario y los objetivos de la organización debe discurrir en el mismo plano.

En este campo, la determinación de la voluntad política es esencial porque, como bien se reconoce en el documento "los dirigentes políticos son los principales agentes movilizadores para ajustar la creación de capacidad en la Administración pública a los objetivos nacionales de desarrollo"185. Si el timón de la nave no se coloca en la dirección adecuada, ésta no llegará al puerto de destino. Y quién dirige la orientación del timón tiene la responsabilidad

\footnotetext{
182 Documento, cit, p. 1.

183 Ibidem.

184 Ibidem.

185 Ibidem.
} 
de que el navío, y quienes en el laboran, estén perfectamente armonizadas en función del rumbo y destino del barco. Es lo mismo que ocurriría si una orquesta dispusiera de los mejores músicos e instrumental pero faltase la dirección. Nunca se podría interpretar el concierto en proporción a la calidad de los instrumentos y a la pericia de los músicos. En el mismo sentido, "es difícil revitalizar la Administración pública de un país sin contar con dirigentes eficaces y decididos" 186 , porque, siendo trascendentes los marcos institucionales, quienes impulsan el proceso de cambio son, obviamente, quienes están al frente: los políticos.

Por tanto, reforma de las políticas públicas y compromiso de los dirigentes, "son requisitos esenciales para la formulación de una estrategia de fortalecimiento de la capacidad del capital humano con el fin de revitalizar la Administración pública de un país"187.

Siendo, como es, fundamental la capacidad de los recursos humanos, del personal, resulta que hemos de poner el punto de mira en la sociedad y reconocer que si la Administración pública no goza del adecuado prestigio entre la gente porque resulta que su labor no se identifica, ni con el progreso social, ni con la mejora de las condiciones de vida de los ciudadanos, entonces hay poco, muy poco que hacer para que la valoración social de la Administración pública sea la que tiene que ser.

Esta afirmación nos lleva inexorablemente al convencimiento de que esta cuestión y, en general, las políticas públicas de personal, son tareas de largo plazo. Por supuesto que se requiere el compromiso político porque el cambio en la percepción social de la Administración pública "está más relacionado con el cambio de valores y actitudes que con la adquisición de nuevos conocimientos y aptitudes por parte del personal"188. Igualmente, para detener la leva de personas que abandonan el servicio público, es necesario, "una planificación amplia y la creación de ministerios y departamentos de sistemas de alta calidad dedicados exclusivamente a la gestión de los recursos humanos" ${ }^{189}$. Y, sobre todo, es imprescindible establecer un entorno propicio para, insisto, recuperar

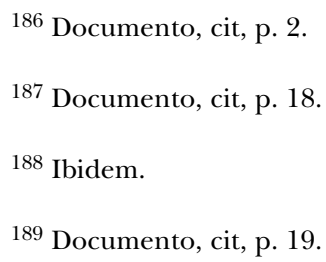


el orgullo del servicio público, orgullo que si se proyecta sobre la ciudadanía y no se agota en sí mismo dando amargos frutos de corporativismo, puede coadyuvar a colocar la cuestión en sus justos límites.

En este contexto, es también menester que las retribuciones sean dignas y que el profesionalismo esté fundamentado en la competencia, en la ética y en la imparcialidad. Asimismo, el sistema de selección y promoción profesional en la función pública debe estar presidido por el mérito, Y, como opinión personal, me atrevería a sugerir el modelo de estabilidad dinámica, de manera que los funcionarios sean evaluados periódicamente. En este campo, un modelo adecuado de capacitación es un factor fundamental del cambio en la Administración pública porque "no se puede reformar ni revitalizar la Administración pública sin aumentar la capacidad del personal" 190 , tarea que implica el desarrollo de los conocimientos, la aptitud, los valores y las actitudes del personal en todos los niveles del sector público ${ }^{191}$.

La mejora de la capacidad del personal requiere, dirigentes políticos decididos y preparados. "El compromiso de los dirigentes políticos, por lo tanto, es fundamental para formular una estrategia encaminada a reforzar la capacidad del capital humano a fin de revitalizar la Administración pública a nivel nacional" ${ }^{\prime 192}$.

En fin, en esta esencial labor, el programa de N.U. en materia de Administración pública y finanzas tiene un papel muy importante y está cosechando grandes éxitos, sobre todo en lo referente a buscar mecanismos que permitan a las Administraciones públicas retener y atraer al mejor personal, a examinar las estrategias de contratación y los incentivos a fin de que el empleo público sea también atractivo a graduados jóvenes y de talento, a reforzar la planificación de recursos humanos en la función pública, a fortalecer la infraestructura ética y, finalmente, a promover la incorporación de una perspectiva de género y el respeto por la diversidad en las estrategias de planificación y de gestión en materia de recursos humanos ${ }^{193}$.

\footnotetext{
190 Ibidem.

191 Ibidem.

192 Ibidem.

${ }^{193}$ Documento, E/C. 16/2004/4.
} 


\section{REVITALIZACIÓN Y SOCIEDAD DEL CONOCIMIENTO}

En el marco de la sociedad del conocimiento, la exigencia de la revitalización de la Administración pública es, si cabe, todavía más clara. Sobre todo porque la sociedad del conocimiento facilita que las organizaciones, también las públicas, sean entornos de aprendizaje permanente y de investigación. De esta manera, como el "conocimiento ha adquirido un mayor relieve"194, es lógico que, en el marco de la Declaración del Milenio, los Gobiernos determinen políticas que, en este campo aporten valor público ${ }^{195}$. Y, en este sentido, servir de elementos catalizadores de revitalización o revalidación de la Administración pública.

En concreto, la versión de la sociedad del conocimiento que interesa transmitir, y que aporta interesantes reflexiones al tema que nos ocupa, es aquella que puede transformar a la Administración pública en una sociedad de conocimiento que procure al máximo el desarrollo humano; que apueste por la apertura, la diversidad, la tolerancia y la inclusión; es primordial el dinamismo; que encuentre puntos de compatibilidad entre el "yo" y el "nosotros"; que potencie el valor de lo público desde el pensamiento abierto; que entienda la trascendencia de que el conocimiento es político y, en definitiva, que promueva valores y criterios éticos.

Desde esta perspectiva, me parece que podemos aprovechar estas virtualidades de la sociedad del conocimiento para apoyar el movimiento revitalizador. En concreto, destacaría que la trascendencia de hacer de los organismos públicos escuelas de aprendizaje facilita aptitudes muy importantes para dar nueva vida a la Administración pública porque permite ser más auto - consciente de sus funciones básicas, contrastarlas sobre la realidad presente, tomar enseñanzas de donde hay modelos exitosos, y obrar en consecuencia. Y, por supuesto, el enfoque de investigación aplicado a la dirección de organizaciones públicas, ayuda sobremanera a estar permanentemente analizando lo que se hace, porqué se hace, así como los resultados obtenidos. De esta forma, se puede corregir el rumbo cuando sea necesario.

En definitiva, la sociedad del conocimiento devuelve la vitalidad perdida de la Administración pública, siempre que ésta, y sus dirigentes, operen en un espacio abierto, plural dinámico y de complementariedad.

\footnotetext{
194 Documento, cit, p. 1.

${ }^{195}$ Documento, E/C. 16/2004.6.
} 


\section{REVITALIZACIÓN DE LA ADMINISTRACIÓN PÚBLICA EN ÁFRICA}

El compromiso de Naciones Unidas con África ha sido, es y será, permanente. $\mathrm{Al}$ menos es lo que se me ocurre escribir en relación con la rúbrica de este epígrafe después de haber participado en varias reuniones de la comisión de Expertos. En todos se ha dedicado un capítulo especial a África, a su Administración pública. Y, todos, y especialmente quien escribe, hemos tenido ocasión de aprender muchas cosas sobre ese apasionante continente al escuchar las atinadas reflexiones de los miembros africanos de la Comisión de Expertos en Administración Pública.

Existe el programa de la Nueva Alianza para el desarrollo de África sobre gestión pública y Administración pública y, recientemente, también Naciones Unidas ha promovido la aplicación de la Carta de la Administración pública en África. Por tanto, hay varias fuentes de conocimiento para situar adecuadamente la pretendida revitalización de la Administración pública en África.

La Declaración sobre la democracia y la buena gestión política económica y empresarial de Durban (2002) reconoció que los problemas más urgentes de África son la reducción de la pobreza y la promoción del desarrollo económico-social y que el marco más adecuado para el trabajo en pro de estos objetivos pasa por la democracia y el buen gobierno. Además, los jefes de Estado africanos reunidos en Durban (2002) señalaron otros retos: Estado de Derecho, equidad, igualdad de oportunidades, igualdad de todos en el ejercicio de las libertades individuales frente a la ley, gobierno justo, honesto, transparente, responsable y participativo, velar por la probidad en la vida pública, combate a la corrupción, estabilidad, paz, seguridad, derechos humanos, protección de los grupos vulnerables: minorías étnicas, mujeres y niños promover la igualdad entre los sexos para potenciar plenamente la capacidad de la mujer ${ }^{196}$. Desafíos, todos ellos, que requieren de una Administración pública y de un Gobierno preparados para esta urgente tarea. La revitalización de la Administración pública en África ocupa, pues, un lugar preferente en la agenda política y administrativa.

Para todo ello, es necesario, me parece, redefinir las misiones del Estado teniendo hoy presentes las condiciones socioeconómicas del espacio local en

196 Documento, cit, p. 17. 
África sin que la descentralización se convierta en un dogma, porque, como hemos señalado, la descentralización es un instrumento, un medio que, según lo casos, podrá ser utilizado siempre que permita mejorar las condiciones de vida de las personas. Probablemente, dadas las circunstancias sociales, el Estado debe jugar un papel más intenso, y extenso, que en las comunidades desarrolladas. Cuando se alcancen los mínimos vitales y se disponga de las instituciones adecuadas, ya se entrará en la consideración del Estado gerente. Por tanto, en el momento presente, la existencia de las instituciones públicas son condición de eficacia para la revitalización buscada.

Además, parece que, en el marco de la diversidad y las tradiciones propias, el constitucionalismo y, por ende, el Estado de Derecho, pueden, y deben, presidir el frontispicio del espacio público en todos los países del continente africano. Esta cuestión algunos la han planteado en términos de conflicto y polémica al entender que el constitucionalismo es un exponente del occidentalismo colonizador y agresivo. La realidad, empero, ha demostrado que Occidente ha aprendido de África, que en África existen instituciones de experiencias genuinamente democráticas y que, en todo caso, el imperio de la ley no es, ni mucho menos, contraria a los valores propios, sino complementaria. Lógicamente, estas cuestiones demandan capacitación y formación adecuada.

Es importante que la introducción de las instituciones políticas clásicas de la democracia no se realice al margen de los ciudadanos. Desgraciadamente, a veces, la población ni conoce ni sabe el para qué de todo lo nuevo. Y, a veces, incluso se produce una distancia tal que no existe legitimación social del nuevo orden jurídico, con los problemas que este tema plantea. Por tanto, es necesario facilitar el conocimiento y promover la integración ciudadana en este proceso, en el que la ejemplaridad de los dirigentes es capital. De lo contrario, bajo forma democrática, se podrá perpetuar un régimen tribal que, en ocasiones, hasta puede producir justo lo contrario de lo que se persigue.

En este marco se deben consolidar el Parlamento, el Gobierno y el Poder Judicial. En concreto, en el marco de la Administración pública, es muy importante que, desde el principio, se predique cotidianamente que la función básica del aparato administrativo es la mejora de las condiciones de vida de los ciudadanos y, especialmente, de los excluidos a desfavorecidos. Es decir, la Administración pública es de propiedad ciudadana y existe para servir a la población. Y, sólo se puede servir objetivamente al interés general, si se garantiza la participación de las personas a las que se debe servir ${ }^{197}$.

197 Documento, cit, p. 18. 
El documento de la Secretaría que ahora comentamos sienta una serie de recomendaciones, entre los que resumo por su trascendencia, las siguientes: ejecución del programa de la Nueva Alianza para el Desarrollo de África sobre gestión pública y administración pública, aplicar la Carta de la Administración pública en África, facilitar la participación libre, fortalecer, en especial, a la institución parlamentaria, despolitizar la Administración pública para hacerla más imparcial, profesional y permanente, y fortalecer, como no, al poder judicial para asegurar la previsibilidad y solución práctica de los conflictos ${ }^{198}$.

\section{REVITALIZACIÓN Y COOPERACIÓN}

Desde la resolución 50/225 de Naciones Unidas, la perspectiva de la cooperación entre lo público y lo privado para el desarrollo es tradicional en el sistema. Para ello, la Declaración del Milenio parte de este enfoque y, en 2002, la Asamblea recomendó que el sistema de Naciones Unidas para el desarrollo prestara asistencia "a los Gobiernos nacionales a fin de crear un clima propicio que fortaleciera los vínculos y la cooperación en el proceso de desarrollo" ${ }^{199}$. Es más, en 2002, la conferencia Internacional sobre la financiación para el desarrollo señaló que "las asociaciones, tanto nacionales como internacionales", son fundamentales para el cumplimiento de los objetivos de desarrollo del Milenio".

El esquema de colaboración se está, pues, aplicando en el campo del crecimiento económico y la reducción de la pobreza, con resultados bien diferentes. Lógicamente hay problemas que se derivan de la falta de capacidad de negociación y de la insuficiencia de las condiciones de mercado, pero las prácticas cooperativas entre Estado, ONGS y sociedad civil son esperanzadoras. "Es necesario que la Administración pública cambie y fortalezca los valores, las actitudes y la capacidad de diálogo con los ciudadanos y que el sector privado cambie y fortalezca su capacidad de composición, pues estos cambios se requieren también de las organizaciones de ciudadanos" ${ }^{200}$.

\footnotetext{
${ }^{198}$ Documento, cit, p. 1.

${ }^{199}$ Documento, cit, p. 2.

${ }^{200}$ Ibidem.
} 
El enfoque, es en mi opinión, adecuado aunque es preciso fortalecer estas alianzas estratégicas desde la rendición de cuentas y la transparencia, "lo que ayudará a recuperar la confianza y el apoyo del público para las políticas y las actividades de los Gobiernos"201. en este sentido, debe aplaudirse que N. U. ayude a los Gobiernos que "permitan que la Administración pública desempeñe un papel esencial en asociaciones responsables y en actividades conjuntas que pongan el cumplimiento de los objetivos de desarrollo del Milenio"202.

Hoy, en un momento en que ya el interés público general ya no se define unilateralmente por el Estado, sino que se hace de forma complementaria entre Poderes públicos y los agentes sociales, es lógico pensar que los objetivos de desarrollo y reducción de la pobreza se contemplen desde la alianza entre lo público y lo privado. Como siempre, debemos aprender los casos que han funcionado bien y analizar porqué en algunos supuestos se han producido estrepitosos fracasos. La sociedad del conocimiento me parece que ayuda a esta tarea.

Probablemente, otra dimensión de la cooperación o colaboración que debe ser destacada es la que hace referencia a las alianzas libres y a las alianzas sesgadas. Lo señalo porque, desde un punto de vista más general, la participación que se orienta o encauza desde el vértice o la cúpula del poder, parece claro que elimina el vector de la libertad. El Estado, a su vez, debe propiciar la existencia de las instituciones sociales con las que va a colaborar. De lo contrario, salvo en supuestos extraordinarios, podríamos pensar que se está operando desde el pensamiento único y desde la perspectiva del mantenimiento y conservación del poder como único objetivo del Gobierno.

En términos generales, "las asociaciones sostenibles tienen objetivos claros y basados en valores, son integradores y responsables, alientan la participación de todos los interesados existe en ellas cierto grado de reciprocidad en las relaciones y sus arreglos operacionales son transparentes y equitativos". Es decir, los esquemas de complementariedad, deben hacer posible que todos, órganos públicos y sociales, vayan de la mano., juntos, en la consecución de mayores cotas de desarrollo humano.

\footnotetext{
${ }^{201}$ Ibidem.

${ }^{202}$ E/C. 16/2001/7.
} 


\section{REVITALIZACIÓN DE LA ADMINISTRACIÓN PÚBLICA Y ES- TADÍSTICA}

Como es habitual en las reuniones de la Comisión de Expertos, la Secretaría presenta un documento sobre datos del sector público. Se agradece porque para formular recomendaciones y consejos, cuanto mejor se conozca la realidad, la tarea será más sencilla y hasta útil. En el caso presente, el documento ofrece datos relativos a gastos e ingresos, no sólo de los Gobiernos centrales, sino también de los niveles inferiores de gobierno. Se lamenta la falta de cuentas generales consolidadas de los Gobiernos y se recomienda otorgar prioridad a la elaboración de estas cuentas y, concretamente, la recopilación de datos sobre gastos por funciones.

Por lo que se refiere a los indicadores, se hizo especial hincapié en los siguientes: gasto de consumo del Gobierno, gasto del Gobierno central, ingresos tributarios del Gobierno central, gastos e ingresos del Gobierno local, total de ingresos tributarios del Gobierno y gastos consolidados del Gobierno.

\section{ACTIVIDADES DE N. U. EN MATERIA DE ADMINISTRACIÓN PÚBLICA}

En términos generales, el programa de Administración pública, Finanzas y desarrollo está en manos de la división correspondiente de N. U. que dirige Guido Bertucci. La Comisión de Expertos apoyó el programa para 2004-2005 y emitió su juicio positivo en relación con las actividades desarrolladas en 2003. El programa, según reza su misión institucional, está destinado a promover la eficiencia, la responsabilidad, la participación y la transparencia de la Administración para la obtención de los objetivos del desarrollo, ahora especialmente vinculados, como es lógico, en la Declaración del Milenio.

El programa se divide por áreas: Gobierno y Administración pública, Gobierno y gestión socioeconómica, gestión del conocimiento y gobierno electrónico y, finalmente redes en Administración pública.

Con independencia de las actividades concretas, que pueden consultarse en la página web de N.U., quiero llamar la atención sobre un enfoque metodológico que me parece particularmente relevante: me refiero a la aproximación multidisciplinar del trabajo en la división y, sobre todo, a la imbricación de la teoría con la práctica. No se teoriza por una parte y, por otra, se estudian 
los casos concretos. No, se trata en las dos perspectivas de forma complementaria como debe ser. La ONU no es una universidad, pero tampoco es una consultora. Por eso son muy útiles los numerosos seminarios que se organizan durante el año así como la promoción de elementos de entendimiento común que puedan ayudar al desarrollo socioeconómico, de los posibles, y humano, de cada persona.

Las tareas de asistencia técnica, de intercambio de experiencias y de información a través de UNPAN son realidades que dicen mucho del trabajo de la división para ayudar a los países en desarrollo en todo lo referente a la Administración pública.

Los expertos también dimos nuestra opinión sobre algunos eventos para N.U. en este campo, como puede ser la reunión de alto nivel promovida por ECOSOC, el proyecto de marco estratégico 2006-2007 en relación con Administración pública y desarrollo y el décimo aniversario de la Conferencia sobre Administración pública.

En definitiva, me parece pertinente que el Comité de Expertos puede sugerir ideas y puntos de vista para abordar el programa del año siguiente.

\section{SOBRE EL TRABAJO DE LA COMISIÓN DE EXPERTOS}

Desde la primera reunión en 2002, la naturaleza del trabajo de la Comisión de Expertos en Administración pública ha planeado sobre todo los encuentros. Sin embargo, me parece que en las sesiones de 2004, tras un polémico debate, las cosas se han aclarado en lo que es posible aclarar.

Por una parte, frente a una propuesta formulada en la reunión de este año, la elaboración de los documentos para estudio en 2005 ( 7 a 14 de abril) se realizará de forma compartida entre los responsables de la Secretaría y los miembros del Comité de Expertos. Es una avance ya que, en mi opinión, la Comisión no se reduce al trabajo en la semana que se reúne en New York, sino que puede, y debe, ayudar a preparar los documentos y, sobre todo, a emitir juicios u opiniones sobre los documentos, proyectos de resolución u otros instrumentos que se le presenten. Y, como órgano consultivo que es, también, "de oficio" puede proponer aquello que estime pertinente para realizar su tarea como Comité de asesoramiento de Naciones Unidas en materia de Administración pública. 
Probablemente, aunque sin ser muy conscientes de ello, ya hemos formulado nuestros puntos de vista y comentarios a los programas de Administración pública en 2002, 2003 y 2004 y al programa marco 2006-2007.

Quizás lo que se nos pidió por parte de algunos observadores presentes en el encuentro en relación con la elaboración de un documento que recoja las opiniones expresadas por el Comité de Expertos, debe pensarse un poco más y formular una metodología que, en efecto, puede facilitar la elaboración del referido documento. 